九州大学学術情報リポジトリ

Kyushu University Institutional Repository

\title{
Induction of Final 0ocyte Maturation and Ovulation in Jack Mackerel, Trachurus japonicus, Temporarily Reared in Captivity
}

Nyuji, Mitsuo

Laboratory of Marine Biology, Graduate School of Bioresource and Bioenvironmental Sciences, Kyushu University

Shiraishi, Tetsuro

Laboratory of Marine Biology, Graduate School of Bioresource and Bioenvironmental Sciences, Kyushu University

Kitano, Hajime

Laboratory of Marine Biology, Graduate School of Bioresource and Bioenvironmental Sciences, Kyushu University

Irie, Susumu

Laboratory of Marine Biology, Graduate School of Bioresource and Bioenvironmental Sciences, Kyushu University

他

https://doi.org/10.5109/25201

出版情報: 九州大学大学院農学研究院紀要. 57 (2)，pp.427-430，2012-09-20. Faculty of Agriculture, Kyushu University

バージョン：

権利関係 : 


\title{
Induction of Final Oocyte Maturation and Ovulation in Jack Mackerel, Trachurus japonicus, Temporarily Reared in Captivity
}

\author{
Mitsuo NYUJI ${ }^{1}$, Tetsuro SHIRAISHI ${ }^{1}$, Hajime KITANO ${ }^{1}$, Susumu IRIE ${ }^{1}$, \\ Akihiko YAMAGUCHI and Michiya MATSUYAMA*
}

\author{
Laboratory of Marine Biology, Division of Animal and Marine Bioresource Sciences, \\ Department of Bioresource Sciences, Faculty of Agriculture, \\ Kyushu University, Fukuoka 812-8581, Japan \\ (Received March 26, 2012 and accepted April 16, 2012)
}

\begin{abstract}
It has been difficult to obtain a stable seed supply of fertilized eggs in jack mackerel in aquaculture because adult female fish do not have well-developed ovaries. Wild fish caught by purse seine usually have atretic ovaries caused by fishing stress, while long-time reared fish often fail to undergo vitellogenesis, possibly due to captivity-induced stress. In the present study, we used wild-caught females that were then reared in sea pens for about 1 month to obtain fish for inducing final oocyte maturation (FOM). A total of 20 females with oocytes of $>500 \mu \mathrm{m}$ diameter were selected, and they were divided into two groups: 16 fish with normally developed oocytes (Group A) and 4 with atretic oocytes (Group B). All fish were injected intramuscularly with human chorionic gonadotropin (hCG; $500 \mathrm{IU} / \mathrm{kg}$ ). In Group A, in which FOM was induced, germinal vesicle migrating oocytes were observed at $25 \mathrm{~h}$ post-injection. Oocytes at the germinal vesicle breakdown, hydration, and ovulation stages were observed at 32, 39, and 39-42 h post-injection, respectively. The water temperature during the experiment was $16.7-17.0^{\circ} \mathrm{C}$. When hCG was injected into fish of Group B, FOM did not occur. Thus, FOM and ovulation could be reliably induced by hCG injection, in temporarily reared females, and the detailed time course of FOM and ovulation of jack mackerel were clarified.
\end{abstract}

Keywords: hCG, jack mackerel, oocyte maturation, ovulation

\section{INTRODUCTION}

The jack mackerel, Trachurus japonicus, belonging to the order Perciformes, family Carangidae, is one of the most important commercially exploited pelagic fish species in the waters aroud Japan. It has been managed in Japan using the total allowable catch (TAC) system since 1997. Detailed biological information, such as age, growth, reproduction, and migration of this target species, is needed to assess and manage the fishery resource. To date, many studies on the biology of jack mackerel have been conducted (Nishida, 2006); however, the information available on its reproductive biology is not sufficient to assess and manage the stock.

Experiments using reared fish often provide information that is useful for better understanding the biology of wild stocks. Recent advances in the knowledge of reproductive physiology and techniques for seed production in finfish have made it possible to breed and raise small pelagic fish in captivity (e.g., Atlantic mackerel Scomber scombrus [Mendiola et al., 2007] and chub mackerel Scomber japonicus [Murata et al., 2005]). By combining survey data with experimental analyses in captivity, we should be able to clarify the actual reproductive and spawning biology of wild stocks.

There are few published studies of rearing experiments with jack mackerel; those that exist were conducted between 1980 and 1983 for seed production (Oka and Mori, 2006). To date, however, there has been no

${ }^{1}$ Laboratory of Marine Biology, Graduate School of Bioresource and Bioenvironmental Sciences, Kyushu University

* Corresponding author (E-mail: rinya_m@agr.kyushu-u.ac.jp) success with stable seed production of jack mackerel. Recently we began a study aimed to establish a suitable experimental system for inducing final oocyte maturation (FOM) and spawning of jack mackerel. We selected jack mackerel with fully grown oocytes (>500 $\mu \mathrm{m}$ diameter) soon after they were caught by purse seine, and attempted to induce FOM by injecting them with human chorionic gonadotropin (hCG); however, the majority of adult females did not undergo FOM because they had atretic oocytes, likely due to fishing stress (Yoda et al., 2006). When we attempted to use adult fish that had been reared in land tanks for over 1 year, female fish failed to undergo vitellogenesis, possibly due to captivity-induced stress (Nyuji et al., 2008). Thus, in jack mackerel FOM and ovulation could not be reliably induced because it has been difficult to obtain females with normal vitellogenic ovaries.

In this study, we temporarily reared wild-caught fish in sea pens to avoid stress caused by fishing or long-term captivity, and could obtain suitable females with normal vitellogenic ovaries for inducing FOM and ovulation although the number of fish is not enough.

\section{MATERIALS AND METHODS}

\section{Animals}

Jack mackerel, caught using a purse seine, were kept for about 1 month in sea pens at a fish farm in Oita Prefecture under natural day lengths and water temperatures. A total of 125 fish were transferred to the Fishery Research Laboratory of Kyushu University, Fukuoka Prefecture, Japan, on 15 May 2006. The following day, fish were anesthetized with 2-phenoxyethanol 
(100 mg/L), and fork length (FL, mm) and body weight (BW, g) were measured. A gonadal biopsy was performed using a plastic catheter (2 mm internal diameter) connected to syringe barrel tubing into the ovarian cavity in order to collect gonadal tissues. In addition, an identification (ID) tag (model TX1400L, DestronFearing Co., MN, USA) was embedded into the dorsal muscle. Ovarian tissues were preserved in Ringer's solution (135 mM $\mathrm{NaCl}, 2.4 \mathrm{mM} \mathrm{KCl}, 1.5 \mathrm{mM} \mathrm{CaCl}, 1 \mathrm{mM} \mathrm{MgCl}_{2}, 1 \mathrm{mM}$ $\mathrm{NaHCO}_{3}, 0.5 \mathrm{mM} \mathrm{NaH}_{2} \mathrm{PO}_{4}$ ) and the diameters of the 20 most advanced oocytes were measured. Consequently, 20 females were obtained with oocyte of $>500 \mu \mathrm{m}$ diameter that showed complete yolk accumulation (Yoda et al., 2006). Other fish were females with immature ovaries or males. After measuring oocyte diameters of 20 fish, the Ringer's solution was discarded and a few drops of Sera clearing solution (ethanol: formalin: acid $=6: 3$ : 1 , $\mathrm{v} / \mathrm{v}$ ) were added to make the cytoplasm transparent, allowing us to view the nucleus (geminal vesicle, GV) (Fig. 1). If a GV was not observed, this indicated the onset of oocyte atresia (Mylonas et al., 1997; Shiraishi et al., 2005). Finally, 20 fish were divided into two groups: Group A, 16 fish (276-356 mm FL, 307-513 g BW) possessing normally yolked oocytes of $>500 \mu \mathrm{m}$ diameter (Fig. 1b); Group B, 4 fish (299-306 mm FL, 285-338 g BW) possessing oocytes of $>500 \mu \mathrm{m}$ diameter, most of which were atretic oocytes (Fig. 1c). a



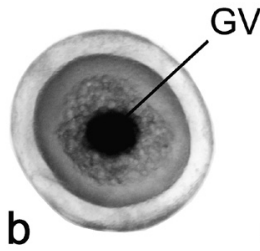

C

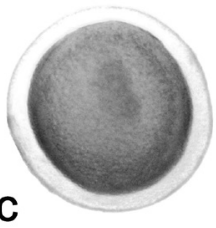

Fig. 1. Photomicrographs of whole oocytes from jack mackerel ovaries. a, oocyte at late yolk (LY) stage in Ringer's solution; b, oocyte at LY stage in Sera clearing solution; c, atretic oocyte in Sera clearing solution.GV, germinal vesicle.

\section{hCG (human chorionic gonadotropin) injection}

Fish in the two groups were injected intramuscularly with hCG (500 IU/kg, GONATROPIN, ASKA Pharmaceutical Co., Tokyo, Japan), dissolved in $0.6 \%$ $\mathrm{NaCl}$ solution at approximately 14:00, followed by Yoda et al. (2006). Sixteen fish in Group A were kept in a 1000-L flow-through seawater tank under a natural photoperiod and at water temperatures of $16.7-17.0^{\circ} \mathrm{C}$. Three to five fish were sampled between 15:00 and 8:00 (i.e., 25 and $42 \mathrm{~h}$ post-injection, respectively). The four fish in Group B were kept in a separate 1000-L tank under the same conditions. One to two fish were sampled at 15:00, 22:00, and 8:00 (25, 32, and $42 \mathrm{~h}$ post-injection, respectively).

\section{Ovarian histology}

After identifying individuals by the ID number on the tag, fish were sacrificed and ovaries were dissected out and weighted. The gonadosomatic index (GSI) was defined as GSI $=100 \times(\mathrm{GW} / \mathrm{BW})$, where GW is gonad weight. Small pieces of ovary were fixed in Bouin's solution, dehydrated, and embedded in Technovit resin (Kulzur, Wehrheim, Germany) for histological study. For light microscopy examination, $3-\mu \mathrm{m}$ thick sections were cut and stained with $1 \%$ toluidine blue solution.

\section{Developmental stages of oocytes}

The morphological characteristics of oocytes in hCG-stimulated jack mackerel can be classified into five stages as follows: (i) late yolk (LY) stage; (ii) germinal vesicle migration (GVM) stage; (iii) germinal vesicle breakdown (GVBD) stage; (iv) hydration (HY) stage; and (v) ovulation (OV) stage. The ovarian stages were represented by the developmental stages of the most advanced group of oocytes. Detailed descriptions are given in the Results.

\section{RESULTS}

A total of 16 female jack mackerel (Group A) with normally yolked oocytes, as determined by gonadal biopsy, and 4 with atretic oocytes (Group B) were selected from 125 wild-caught fish that were reared in sea pens for about 1 month. Just prior to injection (0h, 14:00), females of Group A had oocytes in the LY stage, with a central GV and small oil droplets scattered throughout the cytoplasm (Fig. 2a). Fish with GVMstage oocytes, where the GV was located between the center of the oocyte and the animal pole (Fig. 2c), appeared at $25 \mathrm{~h}$ post-injection (15:00) (Table 1). During the GVM stage, yolk globules at the vegetal pole of the cytoplasm began to fuse with each other. Three out of four fish sampled at $32 \mathrm{~h}$ post-injection (22:00) had oocytes in the GVBD stage, where the nuclear membrane had disappeared and the translucent appearance of the oocyte was likely due to the progression of yolk

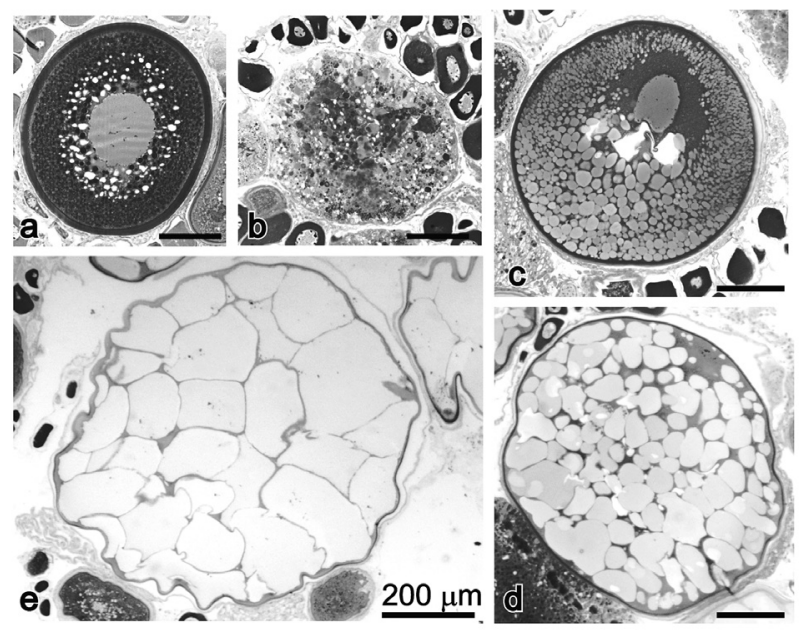

Fig. 2. Photomicrographs of histological sections of jack mackerel oocytes. a, oocyte at the late yolk stage; b, atretic oocyte at the late yolk stage; c, oocyte at the germinal vesicle migration stage; d, oocyte at the germinal vesicle breakdown stage; e, fully hydrated oocyte. 
Table 1. Time course of final oocyte maturation and ovulation of the jack mackerel injected with human chorionic gonadotropin (hCG, $500 \mathrm{IU} / \mathrm{kg} \mathrm{BW}$ ) at $14: 00$ under $16.7-17.0^{\circ} \mathrm{C}$ in water temperature

\begin{tabular}{ccccccc}
\hline Clock time & $\begin{array}{c}\text { Time after hCG } \\
\text { injection }(\mathrm{h})\end{array}$ & & \multicolumn{3}{c}{ Developmental stage of most advanced oocyte } \\
\cline { 4 - 6 } & 25 & 3 & GVM & GVBD & HY & OV \\
\hline 15:00 & 32 & 4 & 1 & 3 & & \\
$05: 00$ & 39 & 5 & & & 4 & 4 \\
$08: 00$ & 42 & 4 & & & & 4 \\
\hline
\end{tabular}

GVM, germinal vesicle migration; GVBD, germinal vesicle breakdown; HY, hydration; OV, ovulation.

proteolysis (Fig. 2d). Four out of five fish sampled at $39 \mathrm{~h}$ post-injection (5:00) had oocytes in the HY stage, where oocytes were almost transparent without degraded $\mathrm{GV}$ and all globules were fused to form yolk plates (Fig. $2 \mathrm{e}$ ). One of the five fish sampled at $39 \mathrm{~h}$ and all four fish sampled at $42 \mathrm{~h}$ post-injection (8:00) had OV-stage ovaries that contained ovulated eggs.

GSI values did not change during the GVM (3.83 \pm 0.51 , mean \pm SEM, $n=4)$ or GVBD $(3.21 \pm 0.91, n=3)$ stages; however, they increased from the GVBD to HY (5.94 \pm $1.08, \mathrm{n}=4$ ) stages due to hydration.

In atretic oocytes, the disintegration of the GV membrane and zona radiata occurred, leaving only the follicular layers (Fig. 2b). When hCG was injected into Group $\mathrm{B}$ fish with atretic oocytes (Fig. 2b), oocyte development did not occur. Oocytes sampled at 25,32 , and $42 \mathrm{~h}$ postinjection (15:00, 22:00, and 8:00, respectively) showed the same histology and diameters as those sampled just prior to injection.

\section{DISCUSSION}

Like the hatchery-reared broodstock of many commercial fish species, female jack mackerel are unable to complete their reproductive cycle in captivity (Oka and Mori, 2006). Previous studies in our laboratory on the annual reproductive cycles of captive jack mackerel have shown that in the majority of females, vitellogenesis does not progress normally in land tanks. Specifically, oocytes were in the pre- or early-vitellogenic stages during the spawning season, even though the fish were of reproductive age and mature size and body condition (Nyuji et al., 2008). When adult males were reared in captivity, spermatogenesis also did not progress normally, even when the histology of the testes showed spermiation. In these males, the GSI were extremely low, and no milt was observed after abdominal massage (Nyuji et al., 2008). In the present study, wild-caught jack mackerel were temporarily reared in sea pens and 16 female fish (Group A) had ovaries with normal yolk formation. Thus, the failure of vitellogenesis could have been influenced differently by the stress of rearing conditions in jack mackerel. Similar dysfunction of vitellogenesis under captive conditions has been reported in other carangid fish, Mediterranean greater amberjack Seriola dumerili (Micale et al., 1999; Mylonas et al., 2004).

In teleost fish, as well as in other vertebrates, ovarian development and recrudescence are regulated by pitui- tary gonadotropins (GtHs), follicle-stimulating hormone (FSH), and luteinizing hormone (LH). In salmonid fish, FSH regulates oocyte development (Planas and Swanson, 2007). FSH stimulation results in the production of estradiol-17 $\beta$ (E2), which in turn stimulates the hepatic production of vitellogenin. After the completion of oocyte growth, a surge in LH secretion causes a decrease in E2 and a dramatic elevation in maturation-inducing hormone (MIH), which induces FOM (Nagahama, 1997; Matsuyama, 2007). The endocrine mechanism that leads to the failure of vitellogenesis in captive-reared jack mackerel is still unclear. To establish an experimental system for inducing FOM and spawning in captivereared jack mackerel, techniques need to be developed to promote vitellogenesis based on endocrinological dysfunction mechanisms in the gonadal development of captive fish.

We measured oocyte diameter and observed the absence of GV to select jack mackerel used for inducing FOM. Jack mackerel with oocytes of $>500 \mu$ m diameter were considered suitable females because this size typically indicates the completion of vitellogenesis (Hotta and Nakashima, 1971). Further, to identify the GV and view clear cytoplasm, oocytes were immersed in Sera clearing solution (Fig. 1). When the GV was not observed, it raised the possibility of onset of atresia in the oocytes. Fish in Group A were selected based on maximum oocyte diameter and the identification of a GV. A single injection of hCG induced FOM in all fish of Group A, which had normally developed and yolk-accumulated oocytes. In contrast, the atretic oocytes of Group B fish did not respond to hCG injection, even though their diameters exceeded $>500 \mu \mathrm{m}$. Therefore, the selection of suitable fish for the induction of FOM and ovulation by hCG treatment requires visual identification of the GV of biopsied oocytes, as well as the measurement of oocyte diameters.

In this study, we showed the time course of hCGinduced FOM and ovulation in jack mackerel at water temperatures of $16.7-17.0^{\circ} \mathrm{C}$ (Fig. 3). We found that GVM, GVBD and ovulation occurred at 25-32 h, $32 \mathrm{~h}$ and 39-42 $\mathrm{h}$ post-injection, respectively. In cultured fish, water temperature affects the duration of latency, i.e., the time between hormone injection and ovulation/spawning (Fortuny et al., 1988; Drori et al., 1994). In general, latency is negatively correlated with water temperature. Nishida (2006) suggested that the mean water temperature of jack mackerel spawning around Japan ranged from $19^{\circ} \mathrm{C}$ to $21^{\circ} \mathrm{C}$. Therefore, if we inject jack mackerel 


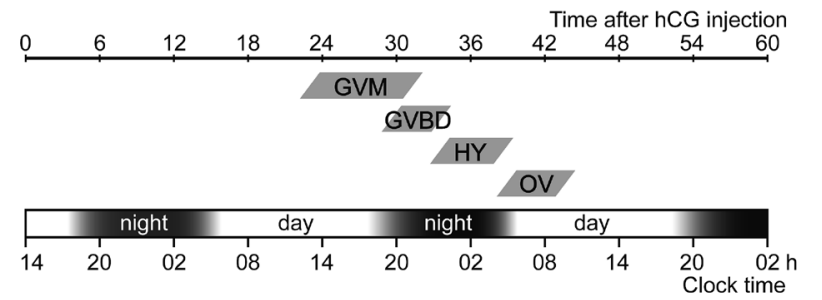

Fig. 3. Time course of final oocyte maturation (FOM) and ovulation after hCG (500 IU/kg) injection. The water temperature during the experiment was $16.7-17.0^{\circ} \mathrm{C}$. GVM, germinal vesicle migration; GVBD, germinal vesicle breakdown; HY, fully hydration; OV, ovulation.

with hCG at these temperatures, the time needed for ovulation become less than $42 \mathrm{~h}$ post-injection. Future experiments outlining how temperature affects latency are necessary.

We could induce FOM and ovulation reliably in the fish which has been reared for a month in sea pens after fishing. The temporary rearing of adult fish may be useful for avoiding stress caused by fishing or long-term captivity. In chub mackerel, we have established the spawning-induction methods using hCG or GnRHa (Shiraishi et al., 2005, 2008; Nyuji et al., 2011) in which female fish were selected by the GV confirmation and oocyte diameter like the present study. Furthermore, spawning frequency in the wild stock of chub mackerel has been estimated based on the postovulatory follicle aging which has been analyzed in the tank experiment (Shiraishi et $a l, 2009)$. In the present study, time course of FOM and ovulation of jack mackerel was clarified. Detailed spawning information of jack mackerel, such as spawning frequency, spawning time and batch fecundity, will be expected to be clarified in future utilizing the methods developed in the present study.

\section{ACKNOWLEDGEMENTS}

We are grateful to the students in the Laboratory of Marine Biology, Kyushu University, for their assistance during the experiment. This study was performed as part of the Establishment of Rearing Systems in Chub Mackerel and Jack Mackerel Program, which is supported by the Fisheries Agency of Japan. These studies were also supported in part by a Grant-in-Aid for Scientific Research (16380136) from the Ministry of Education, Culture, Sports, Science, and Technology of Japan. M. N. is supported by JSPS research by JSPS Research Fellowship for Young Scientist.

\section{REFERENCES}

Drori, S., M. Ofir, B. Levavi-Sivan and Z. Yaron 1994 Spawning induction in common carp (Cyprinus carpio) using pituitary extract or GnRH superactive analogue combined with metoclopramide: analysis of hormone profile, progress of oocyte maturation and dependence on temperature. Aquaculture, 119: 393-407

Fortuny, A., A. Espinach Ros and V. G. Amutio 1988 Hormonal induction of final maturation and ovulation in the sábalo,
Prochilodus platensis Holmberg: treatments, latency and incubation times and viability of ovules retained in the ovary after ovulation. Aquaculture, 73: 373-381

Hotta, H and J. Nakashima 1971 Studies on the structure of the population of jack mackerel, Trachurus japonicus, in the Western Seas of Japan-V. Analyses based on the spawning and maturity. Contributions from the Seikai Regional Fisheries Research Laboratory, 267: 33-50 (in Japanese)

Matsuyama, M. 2007 Follicular steroidogenesis in fish. In "Fish Reproduction" (ed. by M.J. Rocha, A. Arukwe and B.G. Kapoor). Science Publishers, Enfield, NH, pp. 171-199

Mendiola, D., L. Ibaibarriaga and P. Alvarez 2007 Thermal effects on growth and time to starvation during the yolk-sac larval period of Atlantic mackerel Scomber scombrus (L.). J. Fish Biol., 70: 895-910

Micale, V., G. Maricchiolo and L. Genovese 1999 The reproductive biology of the amberjack, Seriola dumerilii (Risso 1810). I. Oocyte development in captivity. Aquac. Res., 30 $349-355$

Murata, O., S. Yamamoto, R. Ishibashi, Y. Oka, H. Yoneshima, K. Kato, S. Miyashita and H. Kumai 2005 Egg development and growth of larval and juvenile cultured chub mackerel Scomber japonicus (Perciformes: Scombridae) in a captive spawning experiment. Aquaculture Sci., 53: 319-324 (in Japanese)

Mylonas, C. C., N. Papandroulakis, A. Smboukis, M. Papadaki and P. Divanach 2004 Induction of spawning of cultured greater amberjack (Seriola dumerili) using GnRHa implants. Aquaculture, 237: 141-154

Mylonas, C. C., L. C. Woods and Y. Zohar 1997 Cyto-histological examination of post-vitellogenesis and final oocyte maturation in captive-reared striped bass. J. Fish Biol., 50: 34-49

Nagahama, Y. 1997 17 $\alpha, 20 \beta$-Dihydroxy-4-pregnen-3-one, a maturation-inducing hormone in fish oocytes: mechanisms of synthesis and action. Steroids, 62: 190-196

Nishida, H. 2006 Reproductive biology of Japanese jack mackerel Trachurus japonicus and Japanese sardine Sardinops melanostictus. Bull. Fish. Res. Agen., Suppl. 4: 113-118 (in Japanese)

Nyuji, M., T. Shiraishi, S. Irie, S. Nii, H. Kitano, A. Yamaguchi and M. Matsuyama 2008 Annual changes in the gonadal histology of captive reared jack mackerel Trachurus japonicus. Sci. Bull. Fac. Agr. Kyushu Univ., 63: 115-123 (in Japanese)

Nyuji, M., T. Shiraishi, S. Selvaraj, V. V. In, H. Kitano, A. Yamaguchi, K. Okamoto, S. Onoue, A. Shimizu and M. Matsuyama 2011 Immunoreactive changes in pituitary FSH and LH cells during seasonal reproductive and spawning cycles of female chub mackerel Scomber japonicus. Fish. Sci., 77: 731-739.

Oka, M. and K. Mori 2006 A review on spawning under captive condition in Japanese horse mackerel Trachurus japonicus. Bull. Fish. Res. Agen., Supple. 4: 151-155 (in Japanese).

Planas, J. V. and P. Swanson 2007 Physiological function of gonadotropins in fish. In "Fish Reproduction" (ed. by M. J. Rocha, A. Arukwe and B. G. Kapoor). Science Publishers, Enfield, NH, pp. 37-66

Shiraishi, T., K. Ohta, A. Yamaguchi, M. Yoda, H. Chuda and M. Matsuyama 2005 Reproductive parameters of the chub mackerel Scomber japonicus estimated from human chorionic gonadotropin-induced final oocyte maturation and ovulation in captivity. Fish. Sci., 71: 531-542

Shiraishi, T., S. D. Ketkar, H. Kitano, M. Nyuji, A. Yamaguchi and M. Matsuyama 2008 Time course of final oocyte maturation and ovulation in chub mackerel Scomber japonicus induced by hCG and GnRHa. Fish. Sci., 74: 764-769

Shiraishi, T., S. D. Ketkar, Y. Katoh, M. Nyuji, A. Yamaguchi and Matsuyama M. 2009 Spawning frequency of the Tsushima current subpopulation of chub mackerel Scomber japonicus off Kyushu, Japan. Fish. Sci., 75: 649-655

Yoda, M., K. Mizuta and M. Matsuyama 2006 Induction of ovarian maturation and ovulation in jack mackerel Trachurus japonicus by human chorionic gonadotropin. Bull. Fish. Res. Agen., 16: 15-18 (in Japanese) 